Supporting Information for

\title{
A Millifluidic Device with Embedded Cross-linked Enzyme Aggregates for Degradation of $\mathrm{H}_{2} \mathrm{O}_{2}$
}

Mahbuba Jannat and Kun-Lin Yang*

Department of Chemical and Biomolecular Engineering, National University of

Singapore, 4 Engineering Drive 4, Singapore 117576

[*] Prof. Kun-Lin Yang

Department of Chemical and Biomolecular Engineering

National University of Singapore

4 Engineering Drive 4

Singapore 117576

Tel: $(+65) 65166614$

Email: cheyk@nus.edu.sg 


\section{$\underline{\text { Calibration curve for } \mathrm{H}_{2} \underline{\mathrm{O}}_{2} \text { quantification }}$}

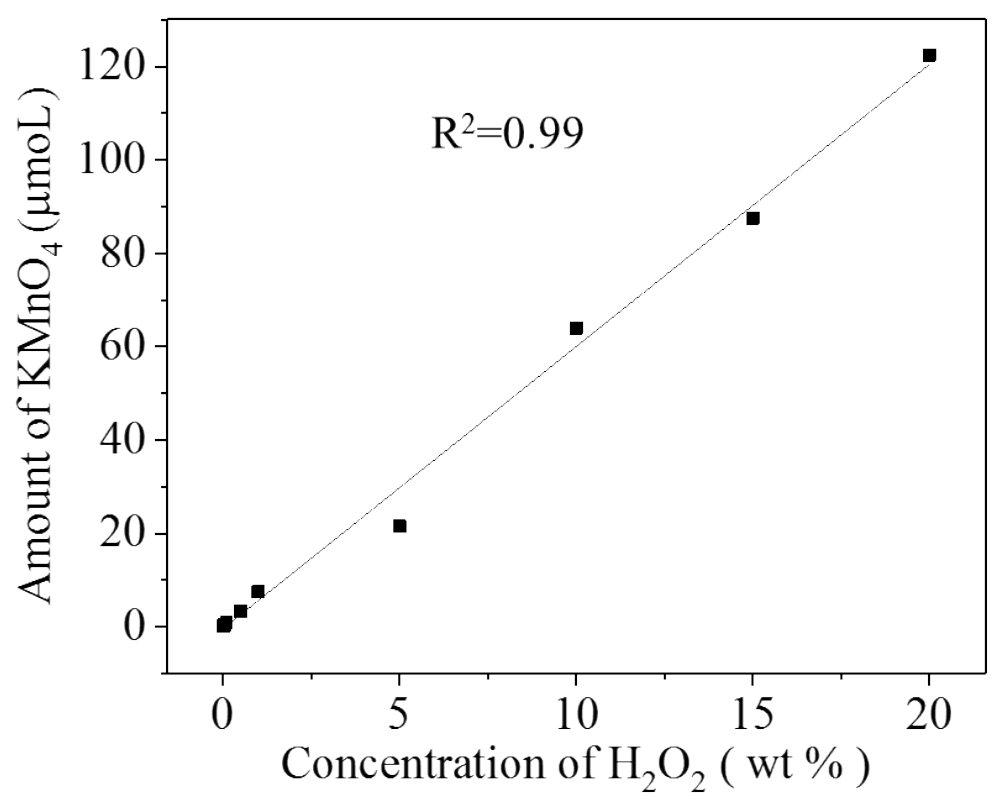

Figure S1. Calibration curve for determination of concentration of $\mathrm{H}_{2} \mathrm{O}_{2}$ by $\mathrm{KMnO}_{4}$ titration. 
